\title{
EXPERIÊNCIAS DE PARTICIPAÇÃO NO SERTÃO ALAGOANO: A CRIANÇA COM VOZ E VEZ NO COTIDIANO DA EDUCAÇÃO INFANTIL
}

\section{PARTICIPATION EXPERIENCES IN SERTÃO OF ALAGOAS: THE CHILD WITH VOICE AND TIME ON THE DAILY LIFE OF EARLY CHILDHOOD}

\section{EXPERIENCIAS DE LA PARTICIPACIÓN EM EL SERTÃO DE ALAGOAS: EL NIÑO CON VOZ Y TIEMPO EN LO COTIDIANO DE LA EDUCACIÓN INFANTIL}

Isaura Lays Sá Fernandes de Souza ${ }^{1}$ Suzana Santos Libardi²

\begin{abstract}
Resumo: A presente pesquisa objetivou compreender se/como ocorre a participação de crianças no cotidiano da Educação Infantil, a partir de estudo de caso numa pré-escola localizada no Sertão de Alagoas. Foram realizadas observação participante e algumas atividades pedagógicas com crianças no ambiente educativo. Uma turma do Jardim I foi envolvida na pesquisa, com 24 crianças na faixa de quatro a cinco anos de idade. As análises dos relatórios de campo refletem o fenômeno da participação de crianças no contexto estudado. Apresentamos as formas pelas quais as crianças agem criativamente e tomam posse do local e da dinâmica em que estão inseridas. São relatadas cenas do cotidiano infantil que nos permitiram pensar analiticamente sobre participação. Observamos que a ação das crianças depende muito do olhar do adulto, pois ele é quem ocupa o papel de prevê-la no processo de ensino e aprendizagem e/ou de, ocasionalmente, não a reconhecer.
\end{abstract}

Palavras-chave: Participação. Criança. Educação Infantil.

Abstract: The present research aims to comprehend if/how children's participation happens in the daily life of Early Childhood Education, from a case study carried out in the Sertão of Alagoas. Participant observation and some pedagogical activities were done with children in a classroom. One Jardim I classroom was involved in the research, with twenty four children from four to five years old. The analysis of the reports of the field work reflects the children participation phenomenon in the studied context. It is shown the ways children act creatively and the ways they take part in the local dynamics they are inserted themselves. It is reported daily life scenes that

\footnotetext{
${ }^{1}$ Secretaria Municipal de Educação de Delmiro Gouveia (SEMED). Delmiro Gouveia, Alagoas, Brasil

2 Universidade Federal de Alagoas (UFAL) - Campus do Sertão. Delmiro Gouveia, Alagoas, Brasil.
} 
allowed us to think analytically about participation. It was observed that children's action depend a lot on the adult's view, one who occupies the role to preview that in the scholar environment and/or does not recognize it, occasionally.

Keywords: Participation. Child. Early Childhood Education.

Resumen: La presente investigación objetivo comprender si/cómo ocurre la participación de las crianzas en lo cotidiano de la Educación Infantil, a partir del estudio de caso en el Sertão de Alagoas. Fueron realizadas observación participante y algunas actividades pedagógicas con crianzas en el ambiente educativo. Un turno del Jardín I fue envuelto en la investigación, con veinte cuatro niños de cuatro a cinco años de edad. Los análisis de los informes de campo reflejan el fenómeno de la participación de niños en el contexto estudiado. Presentan las formas por las cuales las crianzas actúan creativamente y toman pose del local y dinámica en que están insertas. Son relatadas escenas del cotidiano infantil que nos permitirán pensar analíticamente sobre la participación. Observamos que la acción de los niños depende mucho de la mirada del adulto, quien ocupa el papel de proveerle en el ambiente educativo y/o de ocasionalmente no reconocerla.

Palabras clave: Participación. Niños. Educación Infantil.

\section{INTRODUÇÃO}

O presente trabalho aborda a participação de crianças no contexto da Educação Infantil. Foi realizada uma pesquisa para compreender se/como ocorrem formas de participação das crianças no contexto da pré-escola, através de um estudo de caso numa unidade pública municipal de Educação Infantil. Primeiramente, apresentamos algumas reflexões teóricas da Sociologia da Infância e da Pedagogia da Infância a respeito da participação de crianças no ambiente educativo. Depois, apresentamos um recorte de pesquisa empírica (SOUZA, 2019) realizada com o objetivo de pensar a problemática da participação de crianças: ocorre a participação das crianças no contexto estudado? Em caso afirmativo, de que forma ela aparece no cotidiano?

A participação de crianças, seja na pré-escola ou na sociedade, vem sendo defendida no meio acadêmico a partir de um olhar crítico sobre o lugar social tradicionalmente reservado à criança em decorrência dos valores das sociedades modernas. O reconhecimento das crianças como atores sociais foi impulsionado por movimentos diversos de setores da sociedade civil e da academia no sentido de reconceituar a infância para além de sua definição pelo projeto moderno. Dentre eles, acentua-se a Pedagogia da Infância (OLIVEIRA-FORMOSINHO, 2007) e a Sociologia da Infância (SARMENTO, 2007; CORSARO, 2011), que vêm se colocando como abordagens acadêmicas dedicadas à visibilidade do contributo societal de crianças.

Sendo as crianças atores sociais, valorizam-se seus modos de interação e de interpretação de mundo, que constituem as culturas infantis. As culturas de pares resultam das práticas 
cotidianas, dos valores, das rotinas que as crianças produzem e compartilham através das interações com seus pares (CORSARO, 2011). Ao agirem nos seus cotidianos as crianças se constituem como sujeitos e atores sociais, visto que produzem, incorporam e recriam seus olhares sobre o mundo, bem como sobre si e sobre o outro.

Tais concepção e modo de encarar as crianças e suas infâncias defendem a importância de ouvi-las. As crianças são seres capazes de expressar seus sentimentos e suas ideias sobre o mundo que as circunda, e efetivamente o fazem (PINTO, 2007). Pela singularidade do lugar social da infância, o ponto de vista das crianças é único e distinto do de outros grupos sociais; podendo revelar para nós a marca geracional da sua experiência em nossa sociedade. Todavia, no âmbito da pré-escola, cabe a questão de quais encaminhamentos tem tido a expressão da infância.

\subsection{A PEDAGOGIA DA INFÂNCIA COMO UMA PRÁXIS DE PARTICIPAÇÃO}

No limiar do século XXI observamos o movimento perpetrado pela Educação Infantil de construir uma Pedagogia da Infância cujo foco fosse a própria criança. A emergência e a consolidação de uma Pedagogia da Infância que atendesse aos direitos e à educação das crianças, além de seus cuidados em instituições de Educação Infantil, foram defendidas por tal movimento, que propagava a necessidade de se captar as práticas sociais das crianças; historicamente ofuscadas por práticas escolarizantes na creche e na pré-escola (CERISARA et al., 2002).

No Brasil, a história da Pedagogia da Infância foi registrada por Rocha (1998), que buscou analisar os contributos das Ciências Humanas e Sociais na construção de uma pedagogia da Educação Infantil / da Infância. De acordo com a autora, essa pedagogia tem como eixo central a própria criança e seus processos de constituição enquanto ser humano nos contextos sociais e culturais, com suas potencialidades intelectuais, estéticas, expressivas, criativas e emocionais. Essa área do saber possui procedimentos e fundamentos próprios de ação pedagógica e através do real analisa criticamente as crianças e as concepções de infância nos distintos espaços educacionais (ROCHA, 1999).

Oliveira-Formosinho (2007) também nos auxilia a compreender tal pedagogia, a qual segundo a autora configura-se enquanto "[...] uma pedagogia transformativa, que credita a criança com direitos, compreende a sua competência, escuta a sua voz para transformar a ação pedagógica em uma atividade compartilhada." (OLIVEIRA-FORMOSINHO, 2007, p. 14). Nessa perspectiva pedagógica, tanto crianças como os contextos socioculturais que definem sua infância devem ser 
considerados na ação educativa, de modo que sejam o ponto de partida para a organização do trabalho pedagógico; como defendido também por Rocha (1998).

Nesse paradigma pedagógico, enfatizamos o conceito de pedagogia-em-participação criado por Oliveira-Formosinho (2007) que, em semelhança às Pedagogias da(s) Infância(s), defende o exercício de uma práxis pedagógica que responda à complexidade da sociedade, das comunidades, das crianças e de suas famílias, por meio de um processo interativo de diálogo e confronto com as crenças/saberes/práticas educativas, resultantes de um espaço de ação e reflexão.

Para dar suporte aos educadores de infância no conhecimento do seu grupo (a identidade coletiva), de cada criança (a identidade individual) e das respectivas famílias (as identidades socioculturais) é pertinente contextualizar alguns instrumentos metodológicos do cotidiano educativo com as crianças. São eles: observação, escuta, negociação, diálogo e documentação (LUís; ANDRADE; SANTOS, 2015; OLIVEIRA-FORMOSINHO, 2007).

A observação é um artifício imprescindível para o acompanhamento, o planejamento e a avaliação na Educação Infantil. Com a observação os professores podem compreender as maneiras como crianças se expressam, manifestam seus interesses e dificuldades, comunicam suas ações e reagem às mais variadas situações. É um processo contínuo, que também intenta o conhecimento sobre a criança-em-ação (OLIVEIRA-FORMOSINHO, 2007).

Ressalta-se que a observação não se resume ao mero olhar, pois também envolve a escuta. A escuta é um processo de ouvir a criança sobre sua atuação na coconstrução do conhecimento, ou seja, sua colaboração na codefinição da sua própria aprendizagem. A criança que é escutada deve ter também o direito à voz no contexto educacional. Esse fator torna-a mais participativa de modo geral nas atividades educativas (OLIVEIRA-FORMOSINHO; LINO, 2008).

Já o instrumento da negociação implica nas tomadas de decisão serem feitas a partir de parceria adulto-criança. O diálogo entre educadores e crianças deve ser o eixo de tal relação, pois é compreendido como negociação aquilo que passa pelo âmbito do vivido, daquilo que precisamos para sobreviver à rotina já dada, como os horários pré-fixados, as normas estabelecidas, os projetos já pensados e as ações programadas neste contexto (OLIVEIRA-FORMOSINHO, 2007).

Negociação requer espaço de escuta e diálogo. Tratando-se da Educação Infantil, é necessário que o diálogo ocorra intergeracionalmente para o estabelecimento de vínculos afetivos, de atitudes de colaboração e cooperação na construção de um ambiente harmônico; uma vez que a ausência desses preceitos durante o processo de aprendizagem se deve, por exemplo, à falta de relações dialógicas (SILVA; WERLE, 2015). 
O último instrumento pedagógico, citado anteriormente, é a documentação, que descreve o vivido no contexto educativo e completa os outros instrumentos. Documentar é registrar vozes, pensamentos, expressões, sentimentos e vivências das crianças, realçando o meio pelo qual foi apropriado e atribuído significado às suas experimentações (LUÍs; ANDRADE; SANTOS, 2015). Em outras palavras, é a ação de compreender, interpretar e descrever os fazeres pedagógicos e as aprendizagens infantis. Ao registrar o saber construído, coloca-se em diálogo duas culturas que são coexistentes no contexto educativo (a cultura do adulto e a da criança).

\subsection{A PROBLEMÁTICA DA PARTICIPAÇÃO DE CRIANÇAS NA ESCOLA}

A temática da participação - e principalmente a da participação infantil - vem se consolidando e ganhando visibilidade nas investigações científicas no país. Entretanto, tal participação se apresenta como problemática bastante ampla e complexa; entre outros fatores, devido à (in)definição ou às muitas definições do que seja tal participação.

Participação, do latim particeps - aquele que tem parte em, faz parte de, é o ato de opinar, decidir e intervir sobre questões que afetam diretamente o indivíduo e/ou o grupo a que pertence. Soares afirma que "a participação é, sem dúvida, um fator decisivo e poderoso para compreender a exclusão ou inclusão dos cidadãos nos processos de negociação e tomada de decisão acerca dos seus quotidianos." (SOARES, 2006, p. 152). Assim, identificamos que a participação é algo vivido num processo que envolve interação, escolhas, negociações, sendo uma prática da/na relação social, um fenômeno processual engendrado pelos participantes.

Um dos fundamentos legais para a valorização da participação infantil é a Convenção das Nações Unidas sobre os Direitos da Criança (CNUDC), de 1989, que veio salvaguardar os direitos de participação às crianças, ao sustentar que elas são atores sociais e com competências políticas. No Brasil, o movimento de defesa dos direitos específicos de crianças relaciona-se à Constituição de 1988 e ao Estatuto da Criança e do Adolescente (ECA); sendo esse último um instrumento legal para a formalização de nova concepção de criança, como "sujeito político" e "sujeito de direitos"; declarando, assim, as crianças com status próprio de cidadãos.

Dentre os direitos das crianças, a participação tem sido um desafio, o que nos faz questionar como de fato é garantida sua participação nos contextos da família, da escola, da comunidade. E ainda como ela é compreendida no ensino público de Educação Infantil, especialmente 
considerando o momento atual de baixa do financiamento público e precarização da Educação Básica brasileira.

A participação infantil pode ser considerada em dois níveis (Alfageme et al. apud Lima, 2018): a participação simbólica, em que crianças podem ser manipuladas por adultos, por palavras e situações; a exemplo, quando são consultadas sobre determinado assunto, mas lhes é dada pouca ou nenhuma noção sobre; e a participação protagônica, quando a criança pode tornar-se líder e responsável por ações, seja na tomada de decisões ou na sua execução - quando podem reivindicar elas mesmas seus interesses.

Avaliamos, todavia, que entre essas duas modalidades de participação, simbólica e protagônica, há matizes da participação onde se localiza exatamente a complexidade do fenômeno. Também destacamos o perigo de se hierarquizar a participação, pois representaria risco de novamente se valorar o melhor modo, ou o modo certo de participar. Além disso, desconfiamos da presunção de uma participação (de crianças e também de adultos) que, para ser tida como legítima, tenha de ser completamente livre de qualquer interferência ou mediação do outro, como se isso Ihe conferisse mais legitimidade ou originalidade, por exemplo. A ação humana que torna alguém parte de algo será necessariamente atravessada pelo(s) outro(s) da cultura. Crianças e adultos agem pautados em referências de valores, visando o que se quer alcançar, e isso com certeza diz de algo para além de si mesmo, das suas vontades ou idiossincrasias. Nesse sentido, não há participação completamente livre da presença do outro.

Dito isso, concordamos que a questão central é o tipo de ação que o outro tem ou deve ter sobre a participação. No caso da participação de crianças, pensamos sobre qual é o papel dos adultos na participação delas - e não na presunção, como alertou Wyness (2013), de que a saída do mais experiente é sempre condição ou incremento da participação dos mais jovens.

No contexto educacional a participação das crianças tem tido um lugar de destaque, embora Carvalho, Quinteiro e Serrão (2007) pontuem que a discussão não é nova, sendo "uma das mais reivindicadas dimensões do discurso pedagógico da Modernidade [...] tendo em vista a desejada formação para a emancipação do sujeito." (CARVALHO; QUINTEIRO; SERRÃO, 2007, p. 27). Porém, as práticas escolares e propostas pedagógicas que promovem a participação infantil nesse contexto não são uma realidade nacional - em que pese ser um direito formalizado também em documentos nacionais específicos à educação. 
Na seção seguinte descrevemos o método adotado por nós para realização da pesquisa de campo sobre participação junto a crianças da pré-escola. Depois, apresentamos cenas do cotidiano e episódios do trabalho empírico com crianças para analisar se/como as crianças participam.

\section{MÉTODO DA PESQUISA REALIZADA COM CRIANÇAS}

A pesquisa empírica apresentada a seguir foi executada pela primeira autora do presente trabalho, sob supervisão da segunda. O campo envolveu uma instituição pública municipal de Educação Infantil localizada em Delmiro Gouveia, no Alto Sertão do estado de Alagoas — região da bacia hidrográfica do rio São Francisco. A instituição envolvida na pesquisa é vinculada à Secretaria Municipal de Educação (SEMED) e dedica-se exclusivamente à Educação Infantil.

Trata-se de uma escola que foi construída através do reaproveitamento do espaço de uma casa e hoje recebe ao todo 250 educandos. O pátio não era coberto, o que impossibilitava as crianças de brincarem no local quando chovia. Nele havia gangorras e um tipo de brinquedo carrossel - denominado pelas crianças de "gira-gira". Uma das particularidades dessa pré-escola é sua abordagem pedagógica. Em sala, as aulas são executadas a partir de uma rotina composta por atividades permanentes. Observamos as seguintes: "brinquedo livre", acolhida, chamada, "quantos somos?", calendário, roda de conversa, recreação, "leitura deleite". Tanto as atividades em sala quanto as atividades para casa de que tomamos conhecimento são elaboradas com a finalidade de desenvolver as habilidades de escrita, recorte, colagem, desenho e pintura.

As crianças participantes da pesquisa estavam matriculadas em uma turma do Jardim I. Para essa turma empregamos a nomeação "Arco-íris". A turma tinha 24 crianças, sendo 12 meninos e 12 meninas, na faixa etária dos quatro a cinco anos. O grupo participou da pesquisa durante um período de quatro meses. Foram realizados 23 turnos - com quatro horas cada - de observação em sala de aula e no pátio da escola, totalizando 92 horas de permanência na instituição junto às crianças da turma Arco-íris. A realização da pesquisa na referida escola ocorreu em consonância com a realização do estágio da primeira autora do presente trabalho. As tarefas de pesquisadora e de estagiária foram conjugadas por avaliarmos a potencialidade da associação de duas experiências que convergem entre si. Nesse sentido, a experiência de formação docente em questão conjugou prática docente e de pesquisa, valorizando ambas (LÜDKE; CRUZ, 2005).

As crianças participantes desta pesquisa são identificadas aqui por nomes fictícios escolhidos por elas mesmas, durante um momento de diálogo proposto pela pesquisadora. Falamos sobre a 
pesquisa para a turma e pedimos que as crianças escolhessem os nomes a serem atribuídos a elas para constar no trabalho final. Encaramos esse procedimento como uma forma também de elas indicarem interesse em participar da pesquisa. O uso dos nomes fictícios também é necessário para a preservação da identidade das crianças, tendo em vista principalmente o contexto de cidade pequena.

Kramer (2002) reflete sobre esse procedimento metodológico, questionando se o uso de nomes fictícios poderia ser uma forma de autoria ou de anonimato das crianças na pesquisa. Segundo a autora, muitos estudos têm utilizado um referencial metodológico que encara a criança enquanto sujeito da cultura, da história e do conhecimento; porém, isso pode não ser garantido quando as crianças não aparecerem como autoras de suas falas, ações ou produções, quando se utiliza por exemplo a inicial do seu nome verdadeiro, um sobrenome ou um nome fictício. No entanto, ela coloca em questão a dimensão ética e o aspecto jurídico que protegem as crianças por lei, visto que elas se encontram sob proteção e tutela do Estado, em uma instituição pública. Em nossa pesquisa, optamos por utilizar nomes fictícios escolhidos pelas próprias crianças como uma estratégia de, simultaneamente, promover proteção legal e identificação de sua participação na pesquisa; posto que a escolha das crianças por um nome permite certa identidade (elas escolheram como vão aparecer), ao mesmo tempo que só elas e a pesquisadora sabem de tais escolhas.

Realizamos observação participante para compreender a realidade observada e permitir à pesquisadora introduzir-se na situação e observar com vistas a integrar-se progressivamente aos atores sociais, analisando o comportamento verbal e não verbal dos participantes, o que fornece elementos para pensarmos o problema investigado. Em decorrência da conjuntura de nossa inserção na instituição, foram realizadas também atividades de regência na turma Arco-íris. Como exemplo, podemos citar a narração de histórias para introduzir o tema gerador adotado em um dia. Um exemplo dessa atividade ocorreu com o conto "Mariela, a cobra banguela", havendo também uso do tapete interativo agrupando as crianças em círculo. A história foi apresentada por meio de imagens ilustrativas, com as crianças primeiramente fazendo a escuta atenta e, ao fim, fazendo relatos sobre o exposto. Neste dia, o tema era a saúde bucal e o bem-estar do corpo humano. Algumas crianças disseram: "Eu não tenho medo de cobra não, tia." (Elza, quatro anos, trecho do diário de campo). "Eu escovo os meus dentes." (Minnie, cinco anos, trecho do diário de campo). "Minha mãe me leva ao dentista e eu não tenho medo." (Vaqueiro, cinco anos, trecho do diário de campo). "Tia, você sabia que eu gosto de doces? Eu como muitos doces, mas eu escovo os dentes 
todos os dias." (Superman, cinco anos, trecho do diário de campo). "Aqui na escolinha nós também escovamos os dentes." (Frozen, quatro anos, trecho do diário de campo).

Com esse relato, explicitamos que a organização pedagógica e as atividades de aprendizagem fazem parte da dinâmica institucional da pré-escola participante, sendo definida pela mesma. A estagiária (e pesquisadora) adotou um roteiro preestabelecido que seguia o projeto educativo vigente. Houve ocasiões em que complementava a proposta pronta, usando algum material ou estratégia diferente, mas tentando não escapar do que era esperado que as crianças aprendessem. Essa busca, pela estagiária, por acrescentar um diferencial nas atividades partiu do viés da pesquisa contemplada e do confronto entre prática e teoria no seu processo de formação, pois, ao analisar o contexto, percebemos que algumas atividades possuíam um víeis tradicionalista, indo de desencontro ao que é almejado pelas Diretrizes Curriculares Nacionais para a Educação Infantil (DCNEI) (BRASIL, 2010). Essa inquietação nos fez refletir sobre a presença ainda de uma pedagogia tradicional nas instituições educativas de infância, apesar dos discursos contemporâneos defenderem a criança como sujeito ativo e participativo. Avaliamos também que o olhar parcialmente distanciado sobre a rotina pedagógica da pré-escola foi possível, inclusive, pelo viés de pesquisa imprimido à experiência de estágio, quando as estratégias da estagiária-pesquisadora foram no sentido de permitir participação dentro do roteiro fixo institucional.

Para a pesquisadora em campo, tais atividades permitiram que a pesquisa contasse com a confiança e o envolvimento das crianças participantes, e assim pudemos melhor contemplar os modos de interação das crianças. Essa estratégia metodológica, atrelada ao envolvimento da pesquisadora nas brincadeiras e nos jogos dramáticos das crianças, sinaliza a relevância da participação docente nas atividades lúdicas infantis, como indicado por Vargas e Junqueira Filho:

[...] é importante que o professor não apenas observe tais momentos, mas que se permita fazer parte deles, interagindo com as crianças, participando, sempre que convidado ou aceito por elas, do desenrolar dos enredos criados pela lógica do faz de conta e, dessa maneira, possa conhecer as crianças mais de perto, em suas potências e processos de criação, uma vez que a brincadeira revela de quais maneiras as crianças (re)elaboram e (re)constroem o mundo real, apropriando-se dele a partir do seu jeito de brincar com ele, de fantasiar sobre ele, de imaginá-lo e repropô-lo ao tomá-lo como objeto de suas brincadeiras. (VARGAS; JUNQUEIRA FILHO, 2017, p. 174).

O registro das observações no dia a dia, nos momentos de aprendizagem e no pátio, e também das atividades conduzidas com as crianças, foi feito em diários de campo. Todos apontamentos anotados em campo, ao fim das atividades do dia, permitiram a elaboração de 
relatório diário; totalizando 23 relatórios. Os relatos enfocam as crianças, e não a regência, registrando ao máximo possível a ação das crianças nas observações e atividades.

As análises dos relatórios de campo refletem o fenômeno da participação de crianças no contexto estudado. Apresentamos a seguir as formas pelas quais as crianças agem criativamente $\mathrm{e}$ tomam posse do local e da dinâmica em que estão inseridas.

\section{EXPERIÊNCIAS DE PARTICIPAÇÃO: A CRIANÇA COM VOZ E VEZ NO COTIDIANO DA EDUCAÇÃO INFANTIL}

Na pré-escola em questão percebemos as crianças participando de diversas maneiras, sendo algumas formas mais esperadas ou previstas pela instituição - como por exemplo nas atividades pedagógicas conduzidas pelas educadoras, onde é demandado das crianças respostas ou execução de tarefas.

Nessa oportunidade, porém, escolhemos apresentar os modos de participar das crianças que escapavam ao previsto pela organização pedagógica e que faziam com que suas falas ou opiniões fossem escutadas naquele contexto. Essas atitudes eram não previstas pela pré-escola, no sentido de que confrontavam a organização ou a rotina do espaço, por exemplo: choro das crianças quando percebiam que não teriam o desejado, recusa em participar de certas atividades que lhes pareciam não atrativas ou que não aconteciam como desejavam. Destacamos também as quebras de regras, que eram vistas como desobediências, mas também podem sinalizar tensão entre os tempos próprios das crianças e o tempo da rotina escolar. Ressaltamos, ainda, as negociações entre criançacriança e criança-adulto.

Nossa permanência no ambiente educativo permitiu-nos presenciar as respostas das crianças ao outro-adulto sobre as rotinas, os tempos e os espaços adotados pela pré-escola, e o feedback das crianças a essa organização. Por exemplo, quanto à distribuição das crianças nos assentos dos grupos de carteiras. Certo dia, uma das crianças, Amanda, estava caminhando entre as carteiras na sala. Questionamos se a carteira separada para ela fora escolhida por ela. Ela disse que "Não, foi minha mãe que me colocou" (Amanda, quatro anos, trecho do diário de campo). Com o passar das horas, vimos que algumas crianças que têm suas carteiras próximas umas das outras (os grupos de carteiras), acabam constituindo grupos e laços de afinidade, interagindo mais entre si do que com outros colegas da turma, mesmo quando estão fora da sala de aula. Além disso, a escolha do local a se sentar, e, portanto, do grupo a pertencer, não era apenas das mães/pais, mas 
também das professoras, baseada no "mau comportamento" das crianças, constituindo-se como uma estratégia dos adultos.

A nosso ver, a movimentação de Amanda e de outras crianças durante o momento de aprendizagem, de carteira a carteira, pode ser uma maneira de demonstrar que algumas crianças sentem a necessidade de se relacionar com outros colegas, de se distanciar de alguns e mostrar que querem decidir sobre onde e com quem estar. Nos mais simples gestos elas estão a negociar diariamente o compartilhamento do espaço, do tempo e de materiais com outras crianças e também com os adultos - a(s) professora(s).

Outro exemplo ocorreu em uma situação que demandou intervenção das adultas docentes diante da divisão grupal de carteiras, quando o menino identificado como Flash estava sentado sozinho por uns minutos em um dos grupinhos de carteiras. Até que, em certo momento, começou a chorar, pedindo para ir brincar com outros colegas. As professoras conduziram a situação. Ao escutarem o garoto, levaram-no até o grupo de amigos escolhido, mas foi necessária uma negociação entre eles, porque de imediato alguns garotos demonstraram recusa em recebê-lo.

As negociações nesse caso são oportunidades de envolver as crianças na compreensão da situação. Para que os interesses individuais e coletivos fossem articulados, tomando o exemplo do garoto Flash, as docentes fizeram a observação do contexto (identificando que o choro do garoto dizia algo), depois escutaram sua queixa e buscaram dialogar com as outras crianças para negociar.

Tratando-se de um ambiente de Educação Infantil, é imprescindível que essa relação de escuta e diálogo ocorra entre docente e crianças para o ambiente educativo ser saudável, acolhedor e com atitudes de colaboração e cooperação entre os sujeitos. O diálogo entre crianças e educadores é mais que uma troca de experiências. É um processo formativo em que, por meio da linguagem, constrói-se uma teia de relações, sentimentos, ideias, mundos, sonhos, desejos, medos, vivências, segredos (RINALDI, 2012).

A divisão das crianças nos grupos de carteiras impactava na sua interação em jogos e brincadeiras, os quais tendiam a ser separados também pela questão do gênero, tanto no ambiente de aprendizagem quanto no pátio. Num determinado dia, no horário de recreação, brincávamos com as crianças quando algumas começaram a discutir entre si durante um jogo de futebol. Parte das crianças não estava aceitando a entrada de outras na brincadeira - essas outras eram Minnie e Elza. Durante a negociação, o Superman disse que “No nosso gol menina não brinca!" (Superman, cinco anos, trecho do diário de campo). O menino não cedeu a qualquer argumentação utilizada pela pesquisadora-estagiária para as meninas brincarem junto com ele e com os demais alunos. Ele 
dava de ombros, demonstrando insatisfação no decorrer do jogo e quando dois dos seus colegas passaram a bola para as meninas, afirmando com isso a entrada delas no time. Alguns então aceitaram a entrada delas, outros não. Para que fossem incluídas de fato no jogo, Minnie e Elza, junto com a pesquisadora - portanto, "as meninas" - persistiram na tentativa de retirar a bola deles com os pés, correndo atrás da bola para os acompanhar no jogo. A partir da iniciativa de Minnie e Elza, as três "meninas" (crianças e a pesquisadora) começaram a jogar de mãos dadas. A estratégia da pesquisadora foi se incluir enquanto "menina" do time, apesar da sua posição de professora na ocasião, visando indicar aos meninos que brincassem com as meninas da turma. Nesse episódio a adulta tentou minimizar a hierarquia geracional e profissional de sua posição para se aproximar das meninas naquilo que as une, o gênero, e tentar ser parceira para Minnie e Elza, favorecendo sua permanência e participação na brincadeira.

Para nós, a cena representou como as crianças organizavam seus jogos seguindo os critérios de divisão das carteiras e dos brinquedos e brincadeiras indicados a elas como respectivos a meninos ou a meninas. Parte dos meninos parecia refletir isso. Outra parte, não: os meninos que aceitaram Minnie e Elza, jogando a bola para elas, tentando incluí-las no jogo; e elas próprias demandaram participação ao se colocarem querendo jogar bola. Por isso, se por um lado a cena mostra a adequação de crianças às práticas lúdicas destinadas para elas pelos adultos, por outro lado também se colocaram quando insatisfeitas com tal realidade e algumas agiram para reverter a situação.

As crianças também deixaram evidente que possuem tempos próprios e eles não se adequam completamente aos tempos dos adultos e das rotinas escolares. Foi possível perceber, em vários momentos, que elas entendiam o que os adultos esperavam delas e os modos como se comportavam diante dessa expectativa. A narração de uma história infantil em sala de aula, "Cheré, o jacaré de chulé", gerou uma cena relevante para pensar o tempo/rotina e a resposta das crianças. A história falava de um jacaré que ganhou um sapato para usar e, ao fim, tratava da importância da higiene pessoal para uma vida saudável. A partir da leitura da história, foi apresentado à turma, pela estagiária-pesquisadora, um jogo da memória relacionado à temática abordada. Passamos de carteira em carteira, de grupo em grupo, explicando como eram as regras do jogo e às vezes jogando junto, mas as crianças não seguiam as regras estabelecidas. Cada grupo/trio/dupla jogou o jogo da memória de uma maneira diferente da esperada pela condutora. As crianças demonstraram não entender, ou não aceitar, que a maior quantidade de pares obtidos no jogo definia seu ganhador. Elas adotaram o fator quantidade de fichas como critério para vencer a brincadeira, 
independentemente de serem pares ou não. Isso fez com que, quanto mais fichas tinham nas mãos, mais elas queriam; gerando momentos de discussão, pois umas não queriam compartilhar as peças por estarem juntando-as nas mãos, seguindo o critério delas para ganharem o jogo. Após um bom tempo decorrido do início da atividade, as crianças continuaram a jogar harmonicamente, e por mais que eventualmente fosse oferecido outro tipo de brincadeira, elas não quiseram mudar de atividade, permanecendo com o jogo citado até o final do turno.

As crianças tomaram as rédeas do jogo e não satisfizeram as regras postas pela adulta que conduzia a atividade. As crianças comprovaram saber o que queríamos que elas fizessem, mas só evidenciaram isso no dia seguinte, quando antes de distribuir os brinquedos a pesquisadora perguntou quais objetos desejavam usar para brincar. Sereia, uma das alunas, perguntou se o jogo da memória da aula anterior estava no armário dos brinquedos, pois ela queria novamente brincar com ele. Um coletivo de cartas do jogo foi entregue para ela. Outras crianças deixaram seus brinquedos de lado e pediram também um jogo da memória para brincar. Com o jogo distribuído a todos, formamos duplas e explicamos novamente as regras convencionais. Diferentemente do dia anterior, elas começaram a jogar seguindo as regras indicadas, evidenciando que haviam compreendido as instruções dadas e que, naquele momento, estavam dispostas a brincar seguindo as regras originais. Sempre que encontravam os pares de fichas, falavam em voz alta o que cada imagem apresentava e a importância dela, de maneira a mostrar à estagiária-pesquisadora que estavam seguindo o que foi explicado e solicitado pela mesma.

A seu modo, confirmaram que suas aprendizagens não se conjugam no tempo da pré-escola e nem no tempo que o outro-adulto lhes oferece. A partir do ocorrido, entendemos que as crianças burlaram a regra colocada no dia anterior talvez porque estavam mais a fim de brincar da forma criada por elas na hora, impondo-se sobre a direção dada. Esse caso, como exemplo, nos parece uma ação de quebra de regras feita pelas crianças sobre as temporalidades colocadas pela dinâmica institucional. Como elas tomaram as rédeas da situação e conduziram o jogo da forma que desejaram, pensamos que elas participaram ativamente daquela atividade de aprendizagem inclusive por não terem cumprido inicialmente as regras dadas por nós.

Parafraseando Silva (2018), essas atitudes infantis tidas como desobediência são maneiras das crianças, burlando as regras, imporem seu desejo. Outro exemplo refere-se aos momentos de recreação no pátio da pré-escola, quando minutos antes de o tempo se encerrar era solicitado que elas fossem ao banheiro, bebessem algo e guardassem o material levado do espaço de aprendizagem para o pátio, visando ao aproveitamento do tempo para essa organização das 
crianças. As crianças não obedeciam de pronto, somente ao soar da campainha como indicativo do fim do recreio. Os tempos de recreação, livres das paredes dos momentos de aprendizagem, são tão poucos em comparação às necessidades das crianças, que elas não irão perder tempo decidindo entre estar fazendo aquilo que gostam e lhes dá prazer e obedecer às ordens e normas estabelecidas pelos adultos. Essa talvez seja uma participação da criança não prevista pela pré-escola. As rotinas das instituições educativas podem se tornar um complicador quando não há reflexão dos docentes e da gestão escolar sobre os impactos que elas ocasionam às crianças.

A título de ilustrar a relevância do tempo do intervalo; para as crianças, houve ocasiões em que esses momentos foram cancelados devido a fatores externos - chuva molhando a área aberta, tempo muito quente dificultando atividades que exigem esforço físico, pintura das paredes do ambiente escolar - ou pela decisão das professoras da turma. Muitas crianças ficavam indignadas e impacientes quando percebiam que não teriam atividade recreativa, e formulavam argumentos e sugestões sobre o que poderíamos fazer diante de tal situação: "A gente fica nos ladinhos do pátio." (Batman, cinco anos, trecho do diário de campo), se referindo ao corredor e alpendre em frente à sala; “Ôxe, não tem nada não. Se a gente brincar na chuva, depois nossa mãe dá remédio." (Frozen, quatro anos, trecho do diário de campo); "Quando acabar o tempo das outras crianças de ir pro pátio, nós podemos ir se não estiver mais chovendo!" (Homem-Aranha, cinco anos, trecho do diário de campo). O estranhamento das crianças em não poder sair para o intervalo e o movimento adotado, de argumentar sobre, indicaram a relevância de usufruir daquele tempo no pátio. Suas argumentações denotaram sua atividade e sua crença de ter condições de persuadir professoras para que a situação fosse alterada a seu favor. Por vezes, quando não lhes era ofertado por algum motivo o tempo fora do ambiente de aprendizagem, as crianças passavam o dia inteiro questionando as professoras sobre o horário de recreação. Algumas vezes, observamos que elas foram levadas a acreditar que o momento se efetivaria, com um "ar" de suspense; porém próximo ao final das atividades educativas do dia era falado que só teriam recreação em outro dia. Nesses casos, a negociação entre crianças e adultos tendia a não acontecer, quando certas decisões decorriam de escolha feita pelas professoras, de antemão, e a decisão não era participada às crianças adequadamente.

Essa cena é exemplo de uma certa crença, ainda presente em espaços de educação infantil: não levar tão a sério a escuta às crianças, nem o compromisso integral com o consenso de opiniões de adultos e crianças. Algumas vezes isso ocorre por ser comum, no chão da pré-escola, a ideia de que a decisão adulta deve necessariamente valer; como se certos tipos de decisão coubessem 
apenas a eles. Todavia, quando se trata de atividades que interessam às crianças, cabe também a elas protestar, como de fato faziam, no exemplo acima.

De acordo com Pinto:

Instaura-se um conflito caracterizado por resistência, rebeldia e conformismo. As crianças, sendo privadas de participar junto com os adultos da organização do tempo e do espaço de tais informações não conseguem se apropriar desses espaços. Tal fato acaba gerando atitudes de indisciplina que buscam expressar o que sentem por não serem respeitadas em seus próprios interesses. (PINTO, 2007, p. 100-101).

Quando não há negociação, nem o espaço da escuta e do diálogo, não há espaço para a tomada de ações de caráter participativo. Para efetivar e contribuir na construção de atitudes participativas, as instituições educativas que atuam com crianças devem analisar se a organização do tempo e dos espaços educativos está estruturada com vistas a receber e considerar a criança como partícipe do contexto e de seu processo formativo. Concomitantemente,

Com esta opção política e pedagógica explicita-se a importância de a docência na educação infantil intencional e cotidianamente apreender o conteúdo expressadocomunicado pelas crianças de seus pontos de vista e acolhê-los na estruturação e organização do cotidiano. (AGOSTINHO, 2015, p. 77).

A autora nos chama a atenção para refletirmos sobre os modos como as falas e necessidades das crianças são consideradas na rotina dos ambientes de educação de crianças. A rotina pode, por vezes, cercear o seu agir quando engessa seus movimentos e sua criatividade através, por exemplo, da delimitação de um tempo pré-organizado sem a participação das crianças.

Consideramos que no contexto estudado as crianças forçavam participar de modo direto e ativo quando tomavam decisões, tentavam negociar com os outros, escolhendo o que fazer, executando as atividades pedagógicas - inclusive de forma distinta da que os adultos lhe indicaram - ou interagindo com os colegas durante as brincadeiras no pátio e na sala de aula. Esses são exemplos de participações que a pré-escola nem sempre prevê ou percebe como tal. A participação das crianças na Educação Infantil, então, se realiza por diferentes maneiras; seja pelas vozes das crianças, e/ou pelos movimentos que fazem com o corpo, gestos ou expressões que produzem como a circulação entre os grupos/carteiras do ambiente de aprendizagem, ou a manifestação oral de recusa aos objetos disponibilizados ou regras de jogo colocadas. A nosso ver a "quebra" de regras feita por elas, o não obedecer, ou seja, a sua apropriação do que lhes é dado, pode ser sua forma possível de agir diante da condução dada pelos adultos. 


\section{CONSIDERAÇÕES FINAIS}

Para a promoção da participação e da inclusão das crianças na Educação Infantil, faz-se necessário um entendimento acerca das crianças enquanto atores sociais ativos na (re)produção desse espaço. Esse fator foi constatado no decorrer da pesquisa de campo, pois as crianças, apesar de participarem de uma dinâmica pré-escolar já estruturada, refaziam a mesma a partir dos seus modos e jeitos de encarar o ambiente, o tempo e os outros.

Porém, para que crianças se apropriem do ambiente educativo, transformando esse tempoespaço em um lugar de infância, é fundamental ser permitido deixarem suas marcas. Consequentemente, a participação infantil na pré-escola é atravessada necessariamente pelas relações intergeracionais que ali ocorrem.

Há uma distância entre as gerações da infância e da adultez, na organização institucional, que corrobora para a crença de que certas vezes crianças não podem decidir ou fazer certas coisas para as quais só teriam condições "com mais idade". A maturação, nesses casos, é o que permitiria à criança mais velha participar de forma ativa. Essa seria supostamente uma forma mais aprofundada de participação, em contraposição a uma coparticipação, uma participação forjada, manipulativa ou simbólica (quando crianças participam superficialmente).

Como vimos, promover a participação não se tratou necessariamente de introduzir no ambiente da pré-escola atividades completamente originais ou inéditas. Nossa forma de inserção no contexto estudado e pelas atividades pedagógicas executadas permitiu-nos constatar que as crianças agem, seja de forma direta ou não, para terem a sua vez nos processos decisórios sobre o que as interessa ali: escolher seus próprios parceiros, as brincadeiras em que participam, as regras dos jogos, o tempo do pátio, por exemplo. Face às condições pedagógicas criadas, as crianças construíam e reconstruíam suas atividades pedagógicas no cotidiano da pré-escola, como uma forma de cidadania ativa. Elas se colocavam além da participação esperada (aquela nas aprendizagens formais) quando burlavam as rotinas e regras educativas adotadas pela instituição, ampliando a sua participação, no sentido de mostrar suas vozes e desejos naquele ambiente. Tal agência e participação pôde ser vista devido ao olhar adulto (da pesquisa) ter se voltado ao que as crianças estão fazendo com o tempo e a rotina que a pré-escola lhes ofereceu.

Argumentamos que a ação de crianças depende muito do olhar do adulto, pois é quem ocupa o papel de prevê-la no ambiente pré-escolar e/ou de ocasionalmente não a reconhecer. Sendo assim, salientamos a relevância da adesão de práticas pedagógicas que garantam a possibilidade de 
expressão do corpo e dos afetos das crianças enquanto indivíduos na convivência coletiva; uma vez que é por meio do corpo e dos afetos que se intensificam os modos das crianças fazerem parte de algo.

Um possível limitador ou facilitador, para que o espaço seja dado às crianças para uma participação mais efetiva, são as normas dos sistemas de ensino que estruturam e direcionam o fazer pedagógico nos ambientes de educação municipais. O professor de infância, atualmente, depara-se com bastantes materiais prontos para sua execução no dia a dia de aprendizagem. São os projetos temáticos, as sequências didáticas e o recente uso de livro didático para esse nível de ensino - estabelecido pela Base Nacional Comum Curricular (BNCC), com vigência nas instituições educativas municipais da região a partir do ano letivo de 2019.

A BNCC determina as aprendizagens essenciais a que estudantes devem ter acesso, em igualdade de condições, durante a Educação Básica. Ela nos traz campos de experiências, habilidades e competências, entre outros aspectos, que as crianças precisam alcançar; mas na prática parecem não se encaixar com a realidade vivida nas instituições educativas. A BNCC, então, acrescentou recentemente mais tensões ao exercício docente comprometido com a promoção da participação de crianças - visto que colocou novas exigências do âmbito educativo que agregam mais rigidez à rotina escolar - para satisfazer tal demanda, o que dificulta a flexibilidade demandada pelas próprias crianças.

\section{REFERÊNCIAS}

AGOSTINHO, Kátia Adair. A Educação Infantil com a Participação das Crianças: Algumas Reflexões. Da investigação às práticas, 6 (I), 69-86, 2015. Disponível em: http://www.scielo.mec.pt/scielo.php?script=sci_abstract\&pid=S218213722016000100005\&lng=pt\&nrm=iso Acesso em: 08 jan. 2019.

BRASIL. Diretrizes curriculares nacionais para a educação infantil / Secretaria de Educação Básica. - Brasília: Ministério da Educação. Secretaria de Educação Básica, 2010. Disponível em: http://portal.mec.gov.br/dmdocuments/diretrizescurriculares 2012.pdf Acesso em: 08 jan. 2019.

CARVALHO, Diana Carvalho de; QUINTEIRO, Jucirema; SERRÃO, Maria Isabel Batista. Infância na escola: a participação como princípio formativo. In: Participar, brincar aprender: exercendo os direitos da criança na escola / Diana Carvalho de Carvalho, Jucirema Quinteiro, organizadoras. Araraquara, SP: Junqueira \& Marin; Brasília, DF: CAPES, 2007.

CERISARA, Ana Beatriz; OLIVEIRA, Alessandra Mara Rotta de; RIVERO, Andréa Simões; BATISTA, Rosa. Partilhando Olhares Sobre as Crianças Pequenas: Reflexões Sobre o Estágio na Educação 
Infantil. Revista Eletrônica Zero -A- Seis, Florianópolis, v. 05, 2002. Disponível em: https://periodicos.ufsc.br/index.php/zeroseis/article/view/11157 Acesso em: 08 jan. 2019.

CORSARO, William Arnold. Sociologia Da Infância. Trad. Lia Gabriele Regius Reis. Porto Alegre: Artmed, 2011.

KRAMER, Sonia. Autoria e Autorização: Questões Éticas na Pesquisa com Crianças. Cadernos de Pesquisa, n. 116, p. 41-59, julho/ 2002. Disponível em: https://www.scielo.br/pdf/cp/n116/14398 Acesso em: 10 jan. 2019.

LIMA, Letícia Campos De. A Criança como Protagonista na Educação Infantil: Um Olhar Sobre as Práticas Pedagógicas em Delmiro Gouveia-Al. 74 f. Trabalho de Conclusão de Curso (Licenciatura em Pedagogia) - Unidade Delmiro Gouveia-Campus do Sertão, UFAL, 2018.

LÜDKE, Menga; CRUZ, Giseli B. Da. Aproximando Universidade e Escola de Educação Básica pela Pesquisa. Cadernos De Pesquisa, v.35, n. 125, pp.81-109. 2005. Disponível em: http://www2.fe.usp.br/ gpef/teses/grupo 01.pdf Acesso em: 02 de fev. 2019.

LUÍS, Joana De Freitas; ANDRADE, Sofia; SANTOS, Paula Coelho. A Atitude do Educador de Infância e a Participação da Criança Como Referenciais de Qualidade em Educação. Revista Brasileira de Educação, v. 20 n. 61 Abr.-Jun. 2015. Disponível em: http://www.scielo.br/scielo.php?pid=S141324782015000200521\&script=sci abstract\&tlng=pt Acesso em: 02 de fev. 2019.

OLIVEIRA-FORMOSINHO, Júlia. Pedagogia(s) da Infância: Reconstruindo uma Práxis de Participação. In: Oliveira-Formosinho, Júlia; Kishimoto, Tizuko Morchida; Pinazza, Mônica Appezzato (Orgs.). Pedagogia(s) Da Infância: Dialogando com o Passado: Construindo o Futuro. Porto Alegre: Artmed, 2007.

OLIVEIRA-FORMOSINHO, Júlia; LINO, Dalila. Os Papéis das Educadoras: As Perspectivas das Crianças. In: Oliveira- Formosinho Julia. (Org.). A Escola Vista pelas Crianças. Editora Porto, Portugal, 2008. p.70.

PINTO, Maria Raquel Barreto. Tempo e Espaço Escolares: O (Des)Confinamento da Infância. In: Quinteiro, Juricema; Carvalho, Diana Carvalho De. Participar, Brincar E Aprender: Exercitando Direitos da Criança. Araraquara, Sp: Junqueira \& Marin, 2007; Brasília, DF: CAPES, 2007.

RINALDI, Carla. Diálogos com Reggio Emília: Escutar, Investigar e Aprender. 1. Ed. São Paulo. Paz e Terra - 2012.

ROCHA, Eloisa Acires Candal. A pesquisa em educação infantil no Brasil: trajetória recente e perspectiva de consolidação de uma pedagogia. 1998. 187f. Tese (doutorado) - Universidade Estadual de Campinas, Faculdade de Educação, Campinas, SP. Disponível em:

http://www.repositorio.unicamp.br/handle/REPOSIP/251307 Acesso em: 07 jan. 2019.

SARMENTO, Manuel Jacinto. Culturas Infantis e Interculturalidade. In: Dornelles (Org.) Produzindo Pedagogias Interculturais na Infância. Petrópolis, RJ: Vozes, 2007.

SILVA, Conceição Firmina Seixas. Infâncias e Participação nos Campos da Política, das Pesquisas e das Comunidades. Delmiro Gouveia: UFAL, 2018. (Palestra Proferida no Seminário Infâncias e Juventudes em Debate). 
SILVA, Daiana Paz de Oliveira; WERLE, Marta Patrícia Beck. Diálogo e Escuta: A Pedagogia de Paulo Freire para a Educação da Infância. In: IX Seminário Nacional Diálogos Com Paulo Freire: Utopia, Esperança E Humanização. 2015, p. 1-8.

SOARES, Natália Fernandes. A Investigação Participativa no Grupo Social da Infância. Currículo Sem Fronteiras, v. 6, n. 1, P. 25-40, Jan./Jun. 2006. Disponível em: http://www.curriculosemfronteiras.org/vol6iss1articles/soares.htm Acesso em: 02 de fev. 2019.

SOUZA, Isaura Lays Sá Fernandes de. Experiências de participação no sertão alagoano: a criança com voz e vez no cotidiano da educação infantil. 100 f. Trabalho de Conclusão de Curso (Licenciatura em Pedagogia) - Unidade Delmiro Gouveia-Campus do Sertão, UFAL, 2019. Disponível em: http://www.repositorio.ufal.br/handle/riufal/5287 Acesso em: 12 abr. 2019.

VARGAS, Cristina de; JUNQUEIRA FILHO, Gabriel de Andrade. Faz de conta e protagonismo das crianças. In: ALBUQUERQUE, Simone Santos de; FELIPE, Jane Felipe; CORSO, Luciana Vellinho. Para pensar a educação infantil em tempos de retrocessos: lutamos pela educação infantil. - Porto Alegre: Evangraf, 2017, p. 170-187.

WYNESS, Michael. Children's participation and intergenerational dialogue: bringing adults back into the analysis. Childhood, v. 20, n. 4, p. 429-442. 2013. Disponível em:

https://www.researchgate.net/publication/280292528 Children's participation and intergenera tional dialogue Bringing adults back into the analysis Acesso em: 01 out. 2019

\section{SOBRE AS AUTORAS}

\section{Isaura Lays Sá Fernandes de Souza}

Pós-graduação lato sensu (em andamento), Universidade Federal do Vale do São Francisco (UNIVASF); pósgraduação lato sensu (em andamento), Centro Universitário Maurício de Nassau (UNINASSAU); Secretaria Municipal de Educação de Delmiro Gouveia (SEMED) - Alagoas - Brasil.

E-mail: layysfernandes@outlook.com.br

ORCID: https://orcid.org/0000-0002-8919-8775

\section{Suzana Santos Libardi}

Doutorado em Psicologia, Universidade Federal do Rio de Janeiro (UFRJ); Universidade Federal de Alagoas (UFAL) - Campus do Sertão - Brasil; Núcleo de Estudos, Pesquisas e Extensão sobre Diversidades e Educação do Sertão Alagoano (NUDES-UFAL).

E-mail: suzana.libardi@delmiro.ufal.br

ORCID do autor 2: https://orcid.org/0000-0002-2185-6786

Recebido em: 05 de maio de 2020 Aprovado em: 14 de dezembro de 2020 Publicado em: 30 de dezembro de 2020 